\title{
The Influence of Concentration and Temperature on the Formation of $\gamma$-Oryzanol $+\beta$-Sitosterol Tubules in Edible Oil Organogels
}

\author{
Hassan Sawalha • Paul Venema • Arjen Bot • \\ Eckhard Flöter • Erik van der Linden \\ Published online: 20 July 2010 \\ (C) The Author(s) 2010. This article is published with open access at Springerlink.com
}

\begin{abstract}
The gelation process of mixtures of $\gamma$-oryzanol and sitosterol structurants in sunflower oil was studied using light scattering, rheology, and micro-scanning calorimetry (Micro-DSC). The relation between temperature and the critical aggregation concentration (CAC) of tubule formation of $\gamma$-oryzanol and sitosterol was determined using these techniques. The temperature dependence of the CAC was used to estimate the binding energy and enthalpic and entropic contribution to the tubular formation process. The binding energy calculated at the corresponding temperatures and CACs were relatively low, in order of 2 RT $\left(4.5 \mathrm{~kJ} \mathrm{~mol}^{-1}\right)$, which is in accord with the reversibility of the tubular formation process. The formation of the tubules was associated with negative (exothermic) enthalpy change $\left(\Delta H^{0}\right)$ compared with positive entropy term $\left(-\mathrm{T} \Delta S^{0}>0\right)$, indicating that the aggregation into tubules is an enthalpydriven process. The oryzanol-sitosterol ratio affected the aggregation process; solutions with ratio of (60 oryzanol40 sitosterol) started aggregation at higher temperature compared with other ratios.
\end{abstract}

Keywords Organogels $\cdot$ Critical aggregation concentration $\cdot \gamma$-Oryzanol and sitosterol - Tubules . Light scattering $\cdot$ Binding energy $\cdot$ Enthalpy $\cdot$ Entropy

H. Sawalha $(\bowtie) \cdot$ P. Venema $\cdot$ E. van der Linden Laboratory of Physics and Physical Chemistry of Foods, Department of Agrotechnology and Food Sciences, Wageningen University,

Bomenweg 2,

6703 HD Wageningen, The Netherlands

e-mail: hassan.sawalha@wur.nl

\section{A. Bot $\cdot$ E. Flöter}

Unilever Research and Development Vlaardingen,

Olivier van Noortlaan 120 ,

3133 AT Vlaardingen, The Netherlands

\section{Introduction}

Organogels or oil gels have wide potential applications in different fields including foods, pharmaceutics, and cosmetics. ${ }^{1-4}$ The gels are commonly formed through dissolving or dispersing structuring agents that can provide a texture to the oil phase during gelation. Different types of structurants have been used, ranging from polymers and proteins to lower molecular weight compounds such as crystalline tryacylglycerols (TAGs). ${ }^{2,5}$ The last type is often used to structure edible oils for food applications. However, the use of crystalline TAGs in foods is generally considered unhealthy because it contains high levels of saturated fatty acids of which the dietary intake has been associated with an increased risk of cardiovascular diseases. ${ }^{2,5}$ Finding alternatives to crystalline TAGs that have lower content of saturated fatty acids is of primary importance for food industry and has received much attention over the last decade. Several potential structurants were proposed in the literature which can be divided into two categories: single compounds such as monoacylglycerol, diacylglycerol, fatty acids, fatty alcohols, wax, and sorbitan monostearate or mixtures like lecithin with sorbitan tristearate, fatty acids with fatty alcohols, and $\gamma$-oryzanol (sterol ester) with sitosterols (phytosterols). ${ }^{2,5-9}$ Among the aforementioned alternatives, the combination of oryzanol and phytosterols seems quite promising as these materials are derived from edible sources, totally free of saturated fatty acids, and have a cholesterol lowering effect. ${ }^{6,8,10}$ Furthermore, it was reported that mixtures of $\gamma$-oryzanol and $\beta$-sitosterol form translucent, firm, and thermo-reversible gels in sunflower oil even when high structurant concentration is used (i.e., $>16 \%, w / w){ }^{6.7}$ Bot and coworkers found that the firmness and transparency of the gel depend on the oryzanol-sitosterol ratio. ${ }^{6,7,11}$ The haziness of the gel decreased with increasing $\gamma$-oryzanol concentration and the firmest gel was always obtained at the ratio of $\sim 60-40$ 
$w / w$ oryzanol-sitosterol. ${ }^{6-8}$ In other studies, the same group demonstrated that the microstructure of the building block of the gels consists of tubule structures. ${ }^{7,11}$

Currently, information is lacking on the exact mechanism of tubule formation, although it is essential for better understanding of the system. Finding the critical aggregation concentration (CAC) of the tubules as a function of temperature, for example, will provide valuable information regarding the thermodynamics of the system (i.e., binding energy, enthalpy change, and entropy change involved in the formation of the tubules). The fibril formation process in aqueous systems (i.e., protein fibril formation in water) was extensively studied in the literature, and it was reported that the aggregation is entropy-driven process. ${ }^{12}$ The selfassembly process of tubule formation in oil-based systems is, however, barely investigated in the literature and not much is known about aggregation process in these systems.

In this study, the CAC of oryzanol and sitosterol mixtures in sunflower oil was measured as a function of temperature by light scattering, rheometry, and microscanning calorimetry (Micro-DSC). Because formation of the tubules is thermally reversible, the process was considered to be close to thermodynamic equilibrium, and hence, the thermodynamic theories of self-assembly were applied to calculate the corresponding binding energies. ${ }^{12,13}$ Finally, the temperature dependence of the CAC was used to identify whether the formation process of the tubules is an enthalpy or entropy-driven process.

\section{Materials and Methods}

\section{Materials}

In this study, homogenous solutions of $\gamma$-oryzanol (see Figure 1 for chemical structure; Tsuno Rice Fine Chemicals,
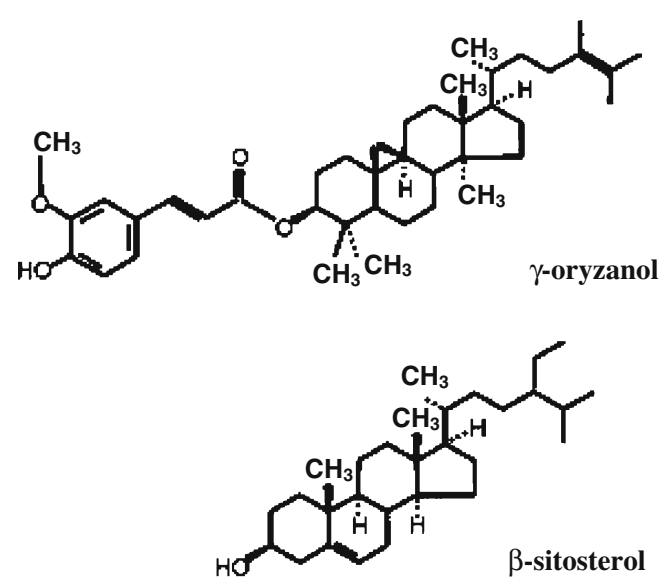

Fig. 1 Chemical structure of the main components of $\gamma$-oryzanol and $\beta$-sitosterol ${ }^{7}$
Wakayama, Japan) and tall oil sterol (78.5\% $\beta$-sitosterol, $10.3 \% \beta$-sitostanol, $8.7 \%$ campesterol, and $3.8 \%$ of other minor sterols, ${ }^{7,11}$ Unilever, The Netherlands) mixtures in sunflower oil (Reddy, NV Vandemoortele, Breda, The Netherlands) were prepared by stirring at $\sim 90{ }^{\circ} \mathrm{C}$ using a magnetic stirrer. The minor sterol compounds present in the tall oil sterol have a very similar chemical structure to the $\beta$-sitosterol, and it was recently found that the gelling behavior and structural properties of their organogels with $\gamma$-oryzanol are similar to $\beta$-sitosterol- $\gamma$-oryzanol organogels. $^{7,11}$ The oryzanol-sitosterol ratio was kept at $60: 40$ $w / w$, except if mentioned otherwise. Concentrations of $8 \%$, $10 \%, 12 \%, 14 \%$, and $16 \% \mathrm{w} / \mathrm{w}$ structurants in sunflower oil were prepared. All materials were used as received.

\section{Light Scattering}

The aggregation process of $\gamma$-oryzanol and sitosterol into tubules in sunflower oil was investigated by using light scattering (LS). The LS measurements were performed using a Malvern (Nano) Zetasizer 3 (Malvern Instruments, UK). The instrument uses non-invasive detection optics which detects the backscattered photons at $173^{\circ}$, which makes the measurement relatively less sensitive to dust compared with scattering at $90^{\circ}$. To follow the formation process of the gel and to find the CAC, a hot and fresh solution was poured in the measuring cell (glass cuvette) and placed in the sample holder that was preheated at $80^{\circ} \mathrm{C}$. The solution in the cuvette was cooled down in stepwise mode from $80{ }^{\circ} \mathrm{C}$ to below aggregation temperature with cooling rate of $2{ }^{\circ} \mathrm{C} /$ step. At each cooling step, the sample was kept for $\sim 8 \mathrm{~min}$ at the target temperature for equilibrium and optimization and after that measurements were taken. Typical measuring time was $10 \mathrm{~s}$, and an average of about 15 measurements was recorded at each step. During each step, the scattered light intensity of the sample was recorded. All samples were measured in duplicate.

\section{Rheology}

The rheology experiments were performed using Anton Paar Modular Compact Rheometer (MCR300) equipped with a coaxial cylinder measuring geometry (CC 17, Couette cell). A fresh and hot solution of the sample was loaded in the cell that was preheated at $80{ }^{\circ} \mathrm{C}$. The sample was cooled down from $80{ }^{\circ} \mathrm{C}$ to $0^{\circ} \mathrm{C}$ at a cooling rate of $0.2^{\circ} \mathrm{C} / \mathrm{min}$. The measurements were performed at strain of 0.001 (i.e., in the linear regime) and frequency of $1 \mathrm{~Hz}$.

\section{Micro-DSC}

The thermal behavior of the gels was investigated using differential scanning calorimeter (DSC) in a Micro-DSC III 
(Setaram, Caluire, France). Of hot and fresh structurant solution, $0.8 \mathrm{ml}$ was poured in preheated sample cell and measured against a reference cell filled with same weight of hot sunflower oil. The sample and the reference cells were placed in the DSC at $80^{\circ} \mathrm{C}$ and kept there for $20 \mathrm{~min}$ and then cooled down to $5{ }^{\circ} \mathrm{C}$ at a cooling rate of $0.2{ }^{\circ} \mathrm{C} / \mathrm{min}$. After that the sample (gel) was heated up from $5{ }^{\circ} \mathrm{C}$ to $95^{\circ} \mathrm{C}$ at a heating rate of $0.5^{\circ} \mathrm{C} / \mathrm{min}$. Finally, the sample was cooled down again to $5{ }^{\circ} \mathrm{C}$ at a cooling rate of $0.2{ }^{\circ} \mathrm{C} / \mathrm{min}$. The transition temperature of aggregation (peak temperature) and temperature and enthalpy of melting were obtained from the DSC thermographs.

\section{Results and Discussion}

\section{CAC with LS}

The scattered light intensity of $8 \%, 10 \%, 12 \%, 14 \%$, and $16 \% \mathrm{w} / \mathrm{w}$ (60 oryzanol-40 sitosterol) solutions in sunflower oil were measured during cooling using LS. Figure 2 shows that the scattered intensity stayed more or less constant during cooling and at a certain temperature, depending on the structurant concentration, a sudden and sharp increase in the intensity was observed (see Figure 2). The change in the intensity was attributed to the formation of tubular aggregates (formation of the gel). The CAC is defined as the concentration where the monomer concentration can increase no further, and addition of more monomers will lead to the formation of the tubular aggregates. ${ }^{13}$ In the present case, the formation of these aggregates leads to the massive increase in light scattering intensity. Based on this, the $\mathrm{CAC}$ was taken as the concentration of the structurant at

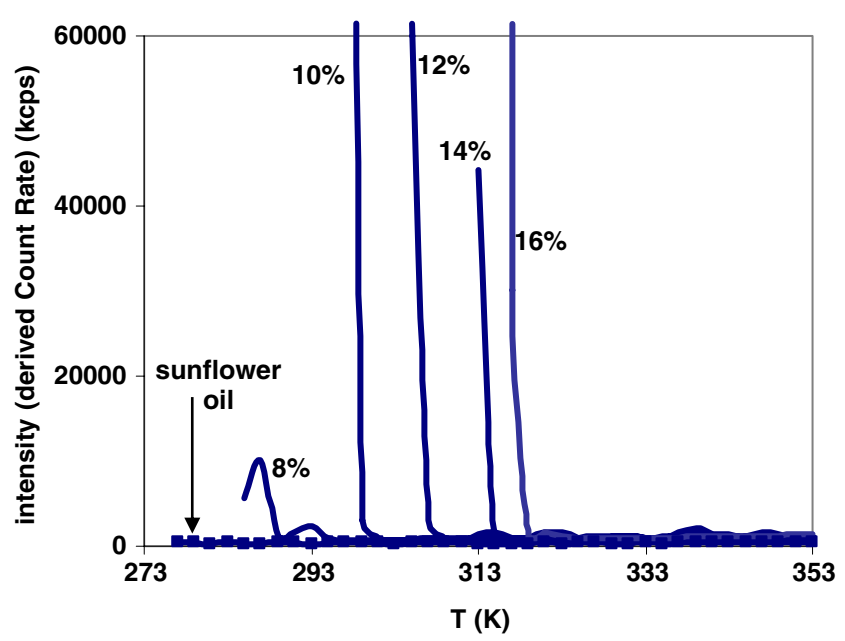

Fig. 2 Scattered light intensity vs temperature during cooling of $8 \%$, $10 \%, 12 \%, 14 \%$, and $16 \% w / w$ (60 oryzanol-40 sitosterol) structurant solutions in sunflower oil as measured by LS which the scattered intensity was sharply and massively increased at the corresponding aggregation temperature. Figure 2 shows also that the aggregation temperature is dependent on the structurant concentration; the aggregation occurred at higher temperature (i.e., earlier in the cooling process) when the structurant concentration was higher. The duplicate experiments of the scattered light intensity showed that the obtained results are reproducible, and the standard deviations were typically less than $10 \%$. Although the tubule formation may appear as nucleation-growth mechanism, the kinetic barrier against nucleation must be small in this system, since we did not find any measurable influence of nucleation on our measurements. This would for instance have shown up as relatively large fluctuation in aggregation temperature due to delay by nucleation events (i.e., the increase in the scattered intensity would occur at different temperature each time).

The formation process of the tubules was further investigated by studying the effects of the oryzanolsitosterol ratio on the formation of the tubules. To do that, solutions of $10 \%$ structurant in sunflower oil with oryzanol-sitosterol ratios of 80:20, 40:60, and 20:80 $w / w$ were tested with LS and compared with the results obtained for the 60:40 ratio. It was found that the oryzanol-sitosterol ratio affects the aggregation into tubules. Table 1 shows that the aggregation took place at different temperatures depending on the ratio. The solution with 60:40 oryzanol-sitosterol ratio showed aggregation at $298 \mathrm{~K}$, whereas with the other ratios, the aggregation was delayed and occurred at lower temperatures during cooling. This may indicate that the oryzanol-sitosterol ratio can influence the size and the structure of the tubular aggregates which possibly explains the effects of the ratio on transparency and firmness of the gel as previously reported by Bot et al.

CAC with Rheology

The formation process of the tubules was also studied with the rheometer and the results were compared with those observed with LS. Figure 3 shows the storage

Table 1 Aggregation temperature as a function of oryzanol-sitosterol ratio

\begin{tabular}{ll}
\hline Oryzanol-sitosterol ratio $(w / w t . \%)$ & Aggregation temperature (K) \\
\hline $20: 80$ & 279 \\
$40: 60$ & 294 \\
$60: 40$ & 298 \\
$80: 20$ & 291 \\
\hline
\end{tabular}

The structurant concentration was kept at $10 \%$ 
Fig. 3 Storage modules $\left(\mathrm{G}^{\prime}\right)$ as a function of temperature (cooling) for $8 \%, 10 \%, 12 \%$, $14 \%$, and $16 \% \mathrm{w} / \mathrm{w}(60$ oryzanol-40 sitosterol) structurant solutions in sunflower oil

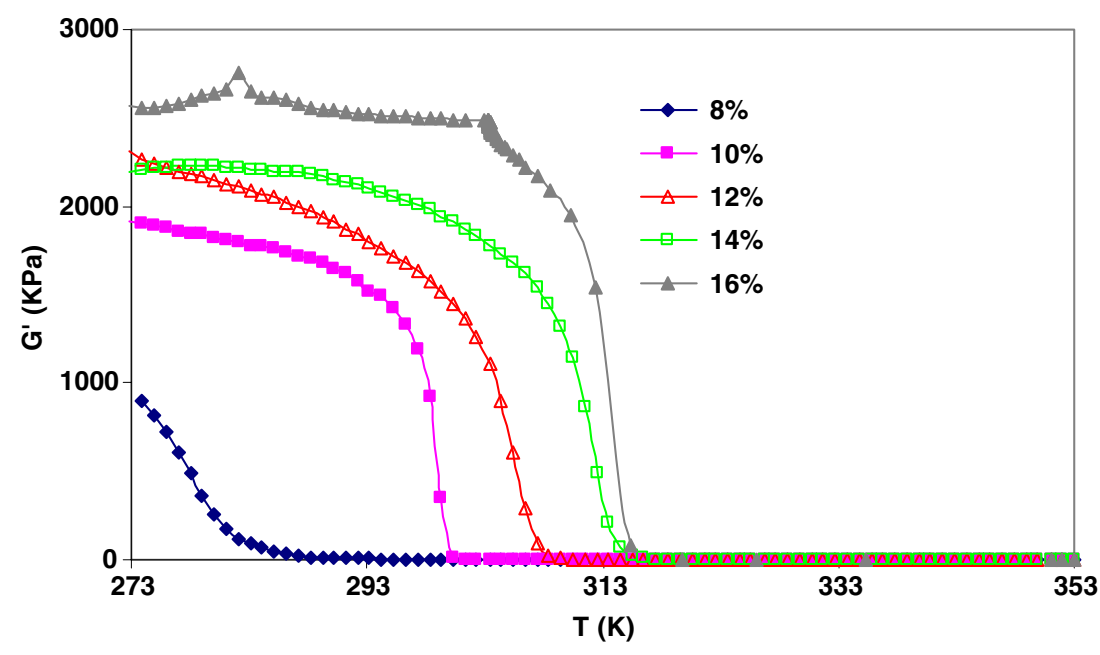

modules $\left(\mathrm{G}^{\prime}\right)$ of the samples as a function of temperature during cooling. The results showed that $\mathrm{G}^{\prime}$ remained constant during cooling of the solution, and at a specific temperature, it dramatically increased indicating the start of the aggregation. The temperature dependence of the CAC obtained with rheology measurements matches well with that observed with LS, which indicates the reproducibility of the CAC measurements. It was noticed that at the aggregation point the $\mathrm{G}^{\prime}$ is always substantially larger than the $\mathrm{G}^{\prime \prime}$ for all tested samples (i.e., $\mathrm{G}^{\prime} / \mathrm{G}^{\prime \prime}>5$ ).

\section{CAC with Micro-DSC}

Besides LS and rheology measurements, the thermal behavior of oryzanol-sitosterol structurant solutions was investigated with Micro-DSC. Figure 4 shows DSC thermographs of $10 \%, 12 \%, 14 \%$, and $16 \% \mathrm{w} / \mathrm{w}(60$ oryzanol-40 sitosterol) structurant solutions in sunflower

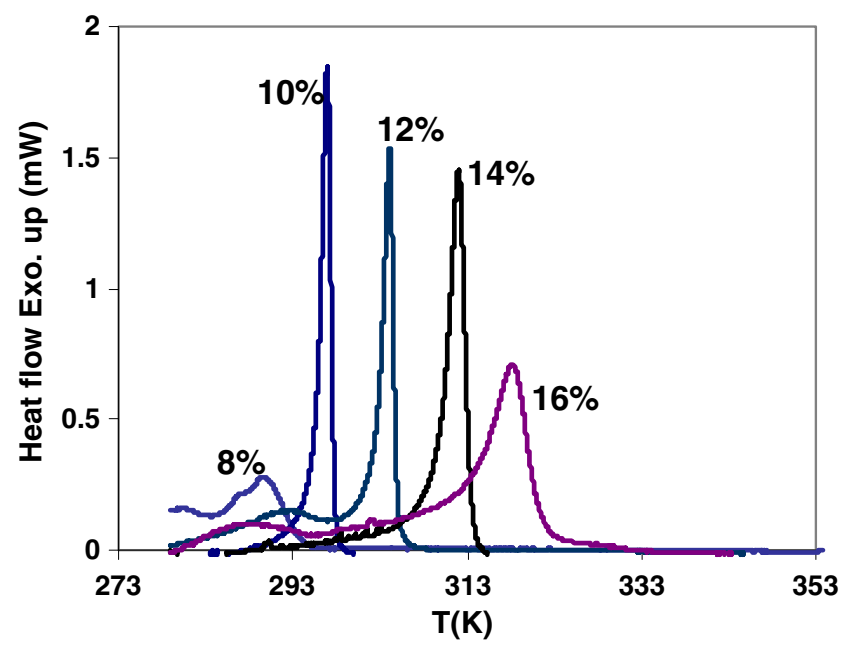

Fig. 4 Micro-DSC cooling thermographs of $8 \%, 10 \%, 12 \%, 14 \%$, and $16 \% \mathrm{w} / \mathrm{w}$ (60 oryzanol-40 sitosterol) structurant solutions in sunflower oil oil. Upon cooling of the sample, an exothermic peak that corresponds to the formation tubule aggregates was observed. In some samples (i.e., $12 \%$ and $14 \%$ ), another small peak was observed after main aggregation peak. This peak could be associated with later aggregation processes which are outside the scope of this paper. Table 2 summarizes the aggregation temperatures (peak temperature) of the samples obtained from Figure 4. The aggregation peak temperature of the second cooling of the sample was similar to the one obtained with the first cooling stage (standard deviation was typically less than $10 \%)$. The results show that the aggregation temperature of the samples observed with the DSC is in a good agreement with that obtained with LS and rheology (see Table 2 for comparison).

\section{Thermodynamic Parameters}

\section{Binding Energy}

The temperature dependence of CAC is used to obtain the thermodynamic parameters related to the aggregation process, i.e., the binding energy, change in Gibbs free

Table 2 Aggregation temperature as a function of structurant concentration measured by Micro-DSC, LS, and rheology

\begin{tabular}{llll}
\hline $\begin{array}{l}\text { Structurant } \\
\text { concentration } \\
(w / \text { wt. \%) }\end{array}$ & $\begin{array}{l}\text { Aggregation } \\
\text { temperature (K) } \\
\text { with Micro-DSC }\end{array}$ & $\begin{array}{l}\text { Aggregation } \\
\text { temperature } \\
(\mathrm{K}) \text { with LS }\end{array}$ & $\begin{array}{l}\text { Aggregation } \\
\text { temperature } \\
(\mathrm{K}) \text { with } \\
\text { rheology }\end{array}$ \\
\hline 8 & 290 & 288 & 287 \\
10 & 298 & 298 & 299 \\
12 & 304 & 306 & 308 \\
14 & 312 & 314 & 315 \\
16 & 318 & 318 & 316 \\
\hline
\end{tabular}

The $\gamma$-oryzanol-sitosterol ratio was kept at $60: 40 w / w$ 
Table 3 The CAC and related thermodynamic parameters (binding energy, change in Gibbs free energy, change in enthalpy, and change in entropy) at corresponding temperatures

\begin{tabular}{lcccccccc}
\hline $\begin{array}{l}\mathrm{CAC} \\
w / w\end{array}$ & $x_{1}, \mathrm{CAC}(\mathrm{mol} / \mathrm{mol})$ & $\mathrm{T}(\mathrm{K})$ & $\alpha(\mathrm{RT})$ & $\alpha\left(\mathrm{kJmol}^{-1}\right)$ & $\Delta G^{0}\left(\mathrm{kJmol}^{-1}\right)$ & $\Delta H^{0}\left[\mathrm{kJmol}{ }^{-1}\right]$ & $\Delta S^{0}\left[\mathrm{kJK}^{-1} \mathrm{~mol}^{-1}\right]$ & $-\mathrm{T} \Delta S^{0}\left[\mathrm{kJmol}^{-1}\right]$ \\
\hline 8 & 0.130 & 288 & 2.04 & 4.88 & -4.88 & -14.34 & -0.03 & 9.46 \\
10 & 0.161 & 298 & 1.83 & 4.53 & -4.53 & -15.35 & -0.04 & 10.82 \\
12 & 0.190 & 306 & 1.66 & 4.22 & -4.22 & -16.18 & -0.04 & -0.04 \\
14 & 0.219 & 314 & 1.52 & 3.96 & -3.96 & -17.04 & -17.97 \\
16 & 0.247 & 318 & 1.40 & 3.69 & -3.69 & -17.48 & -0.04 & 13.08 \\
\hline
\end{tabular}

energy, enthalpy change, and entropy change. For the calculation of the binding energies, it was assumed that in essence one-dimensional tubular aggregates are formed $^{7}$ where the molecules within the tubules stack to each other like the steps in a spiral staircase. According to the thermodynamics of one-dimensional self-assembly, the molar fraction $x_{N}$ of tubular aggregates that consist out of $\mathrm{N}$ building blocks can be expressed as a function of the binding energy using the following equation ${ }^{12,13}$ :

$x_{N}=N\left(x_{1} \times e^{\alpha}\right)^{N}$

where $x_{1}$ is the molar fraction of the monomeric) building blocks that have not been incorporated in the tubules and $\alpha$ is the molar Gibbs free energy of binding in units of RT.

Given the fact that $x_{N}$ cannot be greater than 1 , the product of $\left(x_{1} \times e^{\alpha}\right)$ cannot exceed unity also, meaning that maximum value of which $x_{1}$ can reach is $\sim \mathrm{e}^{-\alpha}$. This leads us to the definition of the CAC of the building blocks which can be stated as $x_{1}, \mathrm{CAC} \approx e^{-\alpha}$. Once the concentration of the building blocks exceeds the CAC, tubular aggregates will start to form. Table 3 shows the binding energies estimated at different temperatures and corresponding

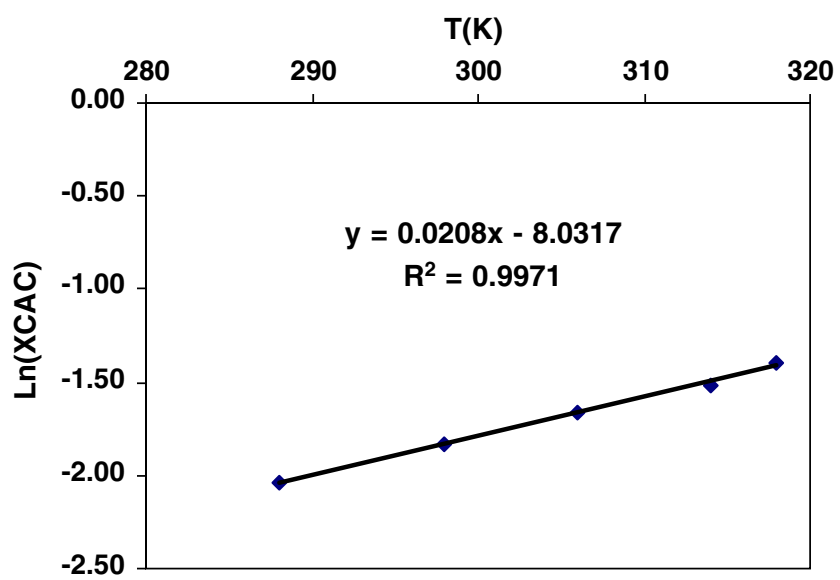

Fig. $5 \ln \left(x_{1}, \mathrm{CAC}\right)$ as a function of temperature for calculations of $\Delta H^{0}$ using Eq. 3
CACs. The results illustrate that the binding energy is rather low, i.e., in order of $\sim 2 \mathrm{RT}\left(4.5 \mathrm{~kJ} \mathrm{~mol}^{-1}\right)$, which is in line with the fact that the formation of the tubules is readily thermo-reversible process.

\section{Enthalpy and Entropy}

The entropy and enthalpy values associated with the formation process were derived from the temperature dependence of the CAC using the following van't Hoff equations $^{12,14}$ :

$\Delta G^{0}=\mathrm{RT} \ln x_{1, \mathrm{CAC}}$

$\Delta H^{0}=-\mathrm{RT}^{2}\left[\frac{\partial \ln x_{1, \mathrm{CAC}}}{\partial T}\right]$

where $\Delta G^{0}$ is the molar Gibbs free energy $\left[\mathrm{kJ} \mathrm{mol}^{-1}\right], \Delta H^{0}$ is the molar enthalpy $\left[\mathrm{kJ} \mathrm{mol}^{-1}\right]$, and $\mathrm{T}$ is the temperature $[\mathrm{K}]$. The molar entropy $\left(\Delta S^{0}\right)\left[\mathrm{kJ} \mathrm{mol}^{-1} \mathrm{~K}^{-1}\right]$, was obtained from the $\Delta G^{0}$ and $\Delta H^{0}$ using the following relation:

$\Delta G^{0}=\Delta H^{0}-T \Delta S^{0}$

Table 4 The temperature and enthalpy of melting of $8 \%, 10 \%, 12 \%$, $14 \%$, and $16 \% w / w$ (60 oryzanol-40 sitosterol) samples (gel) obtained from the heating DSC-curves

\begin{tabular}{llr}
\hline $\begin{array}{l}\text { Structurant concentration } \\
(w / \mathrm{wt} . \%)\end{array}$ & $\begin{array}{l}\text { Melting } \\
\text { temperature }(\mathrm{K})\end{array}$ & $\begin{array}{l}\Delta H \text { melting } \\
\left.[\mathrm{kJmol}]^{-1}\right]^{\mathrm{a}}\end{array}$ \\
\hline 8 & 333 & 7.62 \\
10 & 340 & 11.86 \\
12 & 346 & 11.44 \\
14 & 351 & 14.88 \\
16 & 354 & 14.30 \\
\hline
\end{tabular}

${ }^{\mathrm{a}}$ For the calculation of number of moles, it was assumed that the ratio (60 oryzanol-40 sitosterol) stays the same in formed tubules. Based on this assumption, the average molecular weight of (60:40 oryzaol-sitosterol) was estimated and used to calculate the overall number of moles 
For calculating the $\Delta H^{0}$ values, $\ln x_{1, \text { CAC }}$ was plotted as a function of temperature, and the resulted plot was fitted to a linear relation with $R^{2}>0.99$ (see Figure 5). Table 3 summarizes the enthalpy and entropy of aggregation calculated at different temperatures using Eqs. 2, 3, and 4. The change in enthalpy and entropy increased with increasing temperature. The negative values of the Gibbs free energy $\left(\Delta G^{0}\right)$ show that the formation of the tubules is thermodynamically favored process. Table 3 shows that the change in enthalpy is much larger than that in entropy. The table showed further that the major contribution to the $\Delta G^{0}$ comes from the large negative change in the enthalpy compared with the positive entropy term $\left(-\mathrm{T} \Delta S^{0}\right)$, showing that the formation of the tubules is an enthalpydriven process. This shows that the self-assembly process of tubule formation in oil-based systems is different from that of, i.e., protein fibril formation in aqueous systems which is driven by change in entropy. ${ }^{12}$

\section{Micro-DSC-Temperature and Enthalpy of Melting of the Gels}

The temperature and enthalpy of melting of the gel were obtained from the DSC heating thermograph of the samples, and the results are shown in Table 4. The melting temperature and enthalpy of the gel increased with increasing structurant concentration. The melting enthalpies, as measured by DSC compared to the enthalpy change as determined from the thermodynamics of self-assembly, are found to be slightly lower.

\section{Conclusions}

The temperature dependence of CAC for tubules of $\gamma$ oryzanol and sitosterol mixtures in sunflower oil was obtained by light scattering, rheology, and Micro-DSC, and the results were similar. The binding energy associated with formation of the tubules was quite low, around $\sim 2 \mathrm{RT}\left(4.5 \mathrm{~kJ} \mathrm{~mol}^{-1}\right)$, which is in agreement with the reversibility of the process. The formation of the tubules was found to be an enthalpy-driven process as the change in the enthalpy was the major contributor to the Gibbs energy of the process. This is in contrast to, i.e., proteins fibril formation process in aqueous systems, which is driven by change in entropy. ${ }^{12}$ The formation of the tubules with the solutions of $(60$ oryzanol-40 sitosterol, $w / w)$ started at higher temperatures than solutions with other oryzanol-sitosterol ratios.

Acknowledgment The research described in this paper is financially supported by Food and Nutrition Delta. The authors thank Ing. Anton Korteweg, laboratory of Physical Chemistry and Colloid Science, Wageningen University, for assisting with Micro-DSC measurements and Ing. Jos Sewalt, Food Process Engineering, Wageningen University, for his assistance with LS experiments.

Open Access This article is distributed under the terms of the Creative Commons Attribution Noncommercial License which permits any noncommercial use, distribution, and reproduction in any medium, provided the original author(s) and source are credited.

\section{References}

1. S. Okabe, K. Hanabusa, M. Shibayama, Journal of Polymer Science. Part B: Polymer Physics 43(24), 3567-3574 (2005)

2. M. Pernetti, K.F. van Malssen, E. Flöter, A. Bot, Current Opinion in Colloid and Interface Science 12(4-5), 221-231 (2007)

3. M.A. Rogers, A.J. Wright, A.G. Marangoni, Soft Matter 5(8), 1594-1596 (2009)

4. A. Vintiloiu, J.-C. Leroux, Journal of Controlled Release 125(3), 179-192 (2008)

5. H.M. Schaink, K.F. van Malssen, S. Morgado-Alves, D. Kalnin, E. van der Linden, Food Research International 40(9), 1185-1193 (2007)

6. A. Bot, W.G.M. Agterof, Journal of the American Oil Chemists' Society 83(6), 513-521 (2006)

7. A. Bot, R. den Adel, E.C. Roijers, Journal of the American Oil Chemists' Society 85(12), 1127-1134 (2008)

8. A. Bot, Y.S.J. Veldhuizen, R. den Adel, E.C. Roijers, Food Hydrocolloids 23(4), 1184-1189 (2009)

9. F.G. Gandolfo, A. Bot, A. Flöter, Journal of the American Oil Chemists' Society 81(1), 1-6 (2004)

10. M.B. Katan, S.M. Grundy, P. Jones, M. Law, T. Miettinen, R. Paoletti, Mayo Clinic Proceedings 78(8), 965-978 (2003)

11. A. Bot, R. den Adel, E.C. Roijers, C. Regkos, Food Biophysics 4 (4), 266-272 (2009)

12. A. Kroes-Nijboer, P. Venema, J. Bouman, E. van der Linden, Food Biophysics 4(2), 59-63 (2009)

13. J. Israelachvili, Intermolecular \& Surface Forces, 2nd edn. (Academic, New York, 1992), p. 351.

14. J.-A. Yu, S.-H. Oh, Y.-R. Park, J.-S. Kim, Macromolecular Symposia 249-250(1), 445-449 (2007) 